\title{
ASSESSMENT OF DRUG USE AND EFFECT IN PREGNANT WOMEN ATTENDING ANTENATAL CARE IN HOSPITALS OF MEKELLE, TIGRAY, ETHIOPIA
}

\author{
*Gebremichael Lemlem Gebremedhin ${ }^{1,}$ P. Gomathi ${ }^{2}$ \\ ${ }^{1}$ Pharmacology and Toxicology Course and Research Unit, Pharmacy Department, College of Health Sciences, Mekelle \\ University, Ethopia \\ ${ }^{2}$ Pharmacognosy Course and Research unit, Pharmacy Department, College of Health Sciences, Mekelle University, \\ Ethopia
}

\begin{abstract}
Objectives: To assess the extent and nature of drug utilization among pregnant women attending antenatal care in hospitals of Mekelle, Tigray, Ethiopia.

Methods: Institution-based cross sectional study was conducted by reviewing the antenatal care follow up cards and interviewing pregnant women using semi-structured questionnaire by nurses working in the four hospitals. Details of drugs self utilized and prescribed during the current pregnancy were investigated and categorized according to the United States Food and Drug Administration fetal risk classification. Data was analyzed using SPSS version 20.0.

Result: Of the 400 participants, majority 199 (49.8\%) were in age group of 26-36years. $38(9.5 \%)$ and 8 (2\%) have self utilized modern and herbal drugs, respectively. Majority $26(59.1 \%)$ were analgesics. Most $32(84.2 \%)$ of the self medicated modern drugs were from category $\mathrm{C}$, followed by category B. Illiterates and secondary school complete participants have practiced self medication 3.7 times (AOR $3.65(1.31,10.20), \mathrm{p}=0.014)$ and 4.03 times (AOR $4.03(1.09,14.96)$, $\mathrm{p}=0.038)$ more than the tertiary complete participants, respectively. Self medication use was 3.7 times more among non government employees than governmental employees (AOR $3.68(1.11,12.17), \mathrm{p}=0.033)$. Forty one $(10.2 \%)$ of the participants had chronic diseases where most $26(39.4 \%)$ were from category C, followed by category D $17(25.8 \%)$. Of all the participants, 249 $(62.2 \%)$ consumed one or more prescription drugs, with $1.86 \pm 0.94$ average number of drugs prescribed per pregnant women. Majority $190(76.3 \%)$ were from category B, followed by category C $94(37.8 \%)$, category A 53 (21.3\%), category C/D 23 (9.2\%), category D $22(8.8 \%)$, category B/C $7(2.8 \%)$, category A/C $3(1.2 \%)$ and category X $1(0.4 \%)$. One hundred one $(40.6 \%)$ of the drugs were prescribed in Ayder referral hospital, followed by Mekelle 93 (37.3\%), kalkidan 31 (12.4\%) and Meskerem $24(9.6 \%)$ hospitals. Majority of the drugs prescribed in each hospital were from category B $(80(32.1 \%), 71$ (28.5\%), 21 (8.4\%) and 18 (7.2\%), respectively. Antibacterial drugs were the most commonly prescribed $146(38.7 \%)$.

Conclusion: Majority consumed one or more prescription drugs. Most of them were from category B.

Keywords: pregnancy; self medications; prescription drugs, US FDA fetal risk classification, Hospitals of Mekelle.
\end{abstract}

\section{BACKGROUND}

Ethiopia experiences a heavy burden of diseases with a growing prevalence of communicable and noncommunicable diseases. Many Ethiopians face high disease morbidity and mortality largely attributable to potentially preventable infectious diseases and nutritional deficiencies ${ }^{1}$.

Motherhood is a positive and fulfilling experience for most women. However, more than 20 million pregnancy and child birth are associated with suffering, ill health or death. Every year, approximately 8 million women endure pregnancy related complication(s) and half a million die as a result of many causes, one of which could be inappropriate drug use during pregnancy ${ }^{2}$.

Ethiopia's rate of maternal and newborn morbidity and mortality are among the highest in the world. Current estimate of maternal mortality stands at 673 deaths per 100,000 live births. Direct obstetric complications accounted for $85 \%$ of these deaths as well as countless chronic conditions ${ }^{3}$.

Pregnancy is a time of profound physiological changes in woman's body. These unique changes challenge clinicians managing disease states during pregnancy in the selection of medications best suited to treat their patients. Maternal drug use during pregnancy may pose a teratogenic risk to the fetus and complications to the mother. However, the recommendation to avoid use of all drugs during pregnancy is unrealistic and may be dangerous, which depends on the risk benefit ratio to the mother and fetus.

*Corresponding Author: Gebremichael Lemlem Gebremedhin Pharmacology and Toxicology Course and Research Unit, Pharmacy Department, College of Health Sciences, Mekelle University, P.O.Box: 1871 E-mail:lemlemgd@yahoo.com Cell phone: 0911544198 
Pregnancy should not deter clinicians from providing their patients with appropriate management of their medical conditions; hence prescription in pregnancy is an unusual risk benefit situation ${ }^{4}$.

During pregnancy, women continue to be affected by the usual illnesses that the non- pregnant population faces. In addition there are multiple conditions, some of which directly result from the pregnancy or are worsened by it, that may require pharmacologic treatment. Thus, the health care provider must be aware of appropriate pharmacologic approach for a variety of conditions and the potential impact on the pregnant women and the fetus 5 .

Careful consideration of the benefit to the mother and the risk to the fetus is required while prescribing drugs during pregnancy. Reducing medication errors and improving patient safety are the important areas of discussion ${ }^{6}$. The use of drugs during pregnancy calls for special attention because in this case in addition to the mother, the health and life of her unborn child is also at stake. The drugs given to pregnant mothers for therapeutic purposes may cause serious structural and functional adverse effects in the developing child ${ }^{7}$. Since it is very difficult to determine the effects on pregnant women and the fetus before marketing new drugs due to obvious ethical reasons, almost all drugs are not recommended to be used during pregnancy as much as possible, especially during the first trimester, i.e. when structural developments of the fetus occur ${ }^{8}$.

In developing countries people use herbal medicines routinely in self-care. In many countries programs exist that test safety and efficacy of these medicines and some of them are selected for inclusion in national health programs. However, such system does not exist in Ethiopia despite the wide use of herbal medicines. The production of herbal medicines is commercialized in countries such as china, India, and Thailand and marketing is similar to that for modern pharmaceuticals. But some herbal medicines are potent, and their safety is not as evident as people think ${ }^{9}$.

Information on the use of drugs during pregnancy is scarce and anecdotal. Despite the absence of adequate studies on safety and efficacy of drugs for pregnant women, evidence available shows that physicians prescribe, and pregnant women take a surprisingly large number of drugs. An international investigation sponsored by World Health Organization (WHO) showed that pregnant women ingest an average of three prescription medications during pregnancy (range 1-5). Furthermore, $86 \%$ of the women had taken at least one prescription medication during their pregnancies ${ }^{4}$.

The provision of complete health care necessitates the availability of safe, effective and affordable drugs of the required quality, in adequate quantity all times. The irrational use of drugs has become a serious problem in Ethiopia. Consequences of inappropriate drug use includes increased morbidity and mortality, increased risk of unwanted effects, the emergence of drug resistance, waste of resource, and psychosocial effects ${ }^{9}$.

In the developing world; poor health seeking behavior of patients, delayed initiation of antenatal care (ANC), low level of educational status of mothers, lack of up to date information of health care providers, poor access to health facilities, and loose control over prescription and non-prescription drugs could aggravate irrational use of drugs during pregnancy.

Since there are numerous gaps in knowledge about deleterious consequences for the mother and fetus and the actual practice of drug use by pregnant women should be viewed as a public health issue. Pharmacoepidemiological studies can measure the extent and nature of drug use in pregnant women. The studies conducted in developed countries where drug-prescribing practices are considered to be superior, have identified need for interventional measures aimed at rational prescription during the prenatal period ${ }^{10}$. Similar types of Pharmaco-epidemiological studies auditing the use of drugs during pregnancy have not been conducted in Tigray region, northern Ethiopia. Hence the aim of this study is to examine the extent and nature of drug prescription during pregnancy in four hospitals of mekelle town, Tigray region. With this information, this study intends to provide feedback and recommendations for the health care providers and customers (pregnant and potential to be pregnant).

\section{METHODOLOGY}

\subsection{STUDY AREA}

Tigray is one of the nine regions in Ethiopia. It is found in the northern part of the country. The 2007 Gregorian calendar (GC) census showed the population of the region to be 4.3 million; of which $80 \%$ were rural and $50.75 \%$ of the totals are female. The region is further divided in to five zones including one special zone. These zones are Western, Central, Eastern, and southern Zones. The Special Zone is Mekelle Special Zone. According to the census; Mekelle covers $24.29 \mathrm{~km}$ square and has population of about 214,806 . Mekelle is the capital city of Tigray. It has two governmental hospitals (Quiha hospital and Mekelle hospital) and one referral hospital (Ayder referral hospital) and three private hospitals (Kalkidan hospital, ben Meskerem hospital and Markos hospital).

\subsection{VARIABLES}

\subsubsection{INDEPENDENT VARIABLES}

$\checkmark$ Socio demographic variables (age, marital status, educational status and occupation )

$\checkmark \quad$ Number of Ante Natal Care visits

$\checkmark$ Morbidity/acute or chronic/

$\checkmark \quad$ Level of health facility

$\checkmark \quad$ Prescriber's level of training

\subsubsection{DEPENDENT VARIABLES}

- Class of drugs prescribed

- Number of drugs prescribed per pregnant women

- Extent of self-medication

- Category of self utilized and prescribed drugs 


\subsection{INCLUSION AND EXCLUSION CRITERIA}

2.3.1. Inclusion criteria: participants, who were pregnant, willing and who visited the hospitals for ANC more than two times.

2.3.2. Exclusion criteria: pregnant women, who were not willing and who visited the hospitals for ANC less than twice.

\subsection{STUDY DESIGN}

Institution based cross- sectional study was conducted to get the required information/data.

\subsection{SOURCE POPULATION}

The population constitutes all pregnant women who live in Mekelle during the study period.

\subsection{STUDY POPULATION}

All pregnant women who lived in Mekelle during the study period and attending antenatal care service in the selected hospitals during their current pregnancy. The study participants were sampled from the study population.

\subsection{SAMPLE SIZE DETERMINATION}

The sample size for the study will be determined using single population proportion formula. Since there is no data on prevalence of drug use during pregnancy in the region, $50 \%$ prevalence is used with $95 \%$ confidence level and 5\% tolerable sampling error.

$$
\begin{aligned}
\mathrm{n} & =\frac{(\mathrm{z} \alpha / 2)^{2} \times \mathrm{p} \times(1-\mathrm{p})}{\mathrm{d}^{2}} \\
& =\frac{(1.96)^{2} \times 0.50 \times(1-0.50)}{(0.05)^{2}} \\
& =\mathbf{3 8 4}
\end{aligned}
$$

Taking 10\% compensation for missing or incomplete records it will be: $\mathrm{n}+(\mathrm{n} \times 0.1)$

$$
\begin{aligned}
& =384+(384 \times 0.1)=\mathbf{4 2 2} \\
& \text { n: sample size } \\
& \text { p: prevalence of drug use } \\
& \text { d: tolerable error }
\end{aligned}
$$

\subsection{SAMPLING PROCEDURES}

Random sampling method was used to select the required hospitals in Mekelle. The hospitals found in Mekelle were stratified as governmental and private. From both categories four hospitals (two governmental and two private) were randomly sampled. Proportional numbers of pregnant women were selected by systematic random sampling method using list of attendant pregnant women in each hospital as a sampling frame.

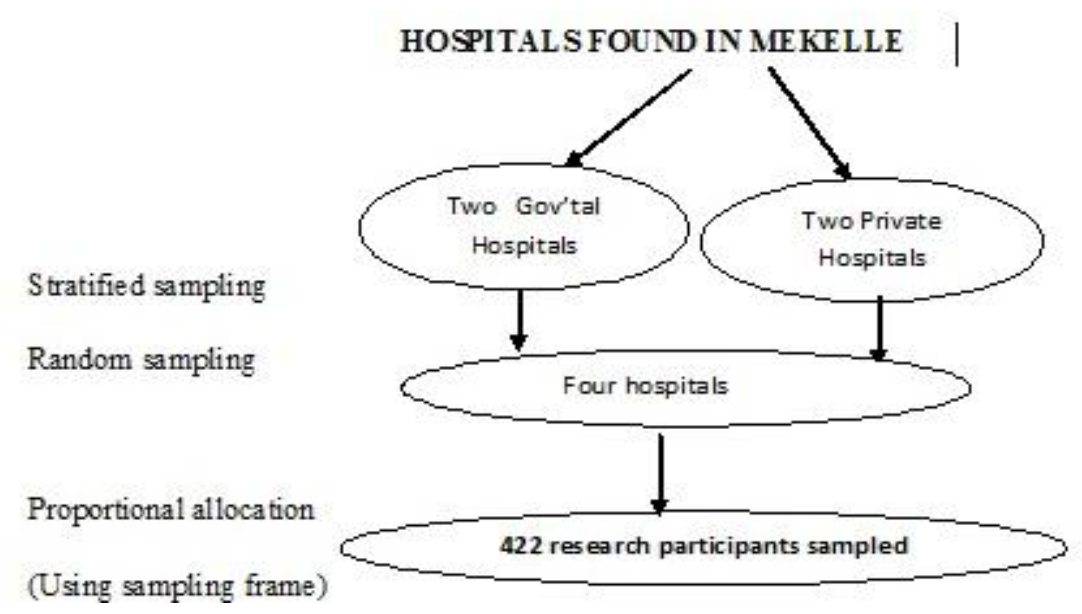

Figure 1: Sampling procedure

\subsection{DATA COLLECTION AND MANAGEMENT}

\subsubsection{DATA COLLECTION INSTRUMENTS}

Data abstraction format and semi- structured questioner was used to collect relevant data from pregnant women follow up medical cards and to interview pregnant women visiting the ANC service to address all the dependent and independent variables under study.

\subsubsection{RECRUITMENT AND TRAINING OF DATA COLLECTORS}

Data collectors who were nurses working in the selected health institutions during the study period and were not involved in prescribing were recruited. They were introduced to the objective of the study and trained on how to use the data collection instruments, the (c) 2011-14, JDDT. All Rights Reserved significance of each question in the instrument and how to present the questions to the respondent in a simple and understandable way.

\subsubsection{DATA COLLECTION}

Data was collected from January 2014 to March 2014. Data on socio demography and self-medication of pregnant women was collected using semi-structured questioner, and data on drugs prescribed using data abstraction format.

\subsubsection{DATA QUALITY ASSURANCE}

In order to develop locally acceptable way of inquiring and maximizing the responses by respondents; questionnaires were pre-tested in health institutions other than the study facilities before the actual data collection. ISSN: 2250-1177 
The pre-test helped us to rectify and revise instruments. The questionnaire and data abstraction format were translated into the common language spoken in the study area (Tigrigna) and back to English to ensure the consistency.

\subsubsection{ETHICAL CONSIDERATIONS}

Ethical approval and clearance was obtained from Mekelle University, College of Health Sciences and Tigray Regional Health Bureau Ethical Review Committees. At all levels, officials were contacted and permission was secured. The necessary explanation regarding the purpose of the study and its procedure, assurance of confidentiality, the right not to participate in the study without any consequences was done to the study population. Participants were assured about confidentiality of the information obtained in the course of the study in that: no personal identifiers were used and data was analyzed in aggregates.

\section{RESULTS}

In this study 400 pregnant women had participated. Majority $199(49.8 \%)$ of the women were in the age group of 26-36 years with the mean age of $1.66 \pm 0.64$ years. Three hundred eighty two $(95.5 \%)$ of the respondents were married and $147(36.8 \%)$ were housewives. Majority139 (34.8\%) of them were college/university graduated (Table-1).

Table 1: Socio-demographic factor of participants ( $\mathrm{n}=400)$, Jan-Mar 2014

\begin{tabular}{|c|c|c|}
\hline Characteristics & Frequency & Percentage $(\%)$ \\
\hline \multicolumn{3}{|l|}{ Age } \\
\hline $15-25$ & 170 & 42.5 \\
\hline $26-36$ & 199 & 49.8 \\
\hline $37-47$ & 29 & 7.3 \\
\hline$>47$ & 2 & .5 \\
\hline \multicolumn{3}{|l|}{ Marital status } \\
\hline Married & 382 & 95.5 \\
\hline Single & 13 & 3.3 \\
\hline Divorced & 5 & 1.3 \\
\hline \multicolumn{3}{|l|}{ Educational status } \\
\hline unable to read and write & 48 & 12.0 \\
\hline only read & 8 & 2.0 \\
\hline only read and write & 20 & 5.0 \\
\hline primary school complete & 82 & 20.5 \\
\hline secondary school complete & 103 & 25.8 \\
\hline college/university graduate & 139 & 34.8 \\
\hline \multicolumn{3}{|l|}{ Employment status } \\
\hline Government employee & 94 & 23.5 \\
\hline non government employee & 49 & 12.3 \\
\hline Merchant & 57 & 14.3 \\
\hline Student & 23 & 5.8 \\
\hline house wife & 147 & 36.8 \\
\hline Unemployed & 29 & 7.3 \\
\hline daily worker & 1 & .3 \\
\hline
\end{tabular}

Of the total pregnancies; $317(79.3 \%)$ of them were planned and $83(20.8 \%)$ were unplanned. Majority 366 $(91.5 \%)$ of the participants were vaccinated. Ninety nine (27\%) of the pregnant women have finished the fifth dose of TT vaccine; of which 33 (33.3\%) were from Meskerem hospital followed by Ayder referral hospital
30 (30.3\%), Mekelle hospital 19(19.2\%) and Kalkidan hospital $17(17.2 \%)$. Eighty five (23.2\%) of them took second dose, $81(22.1 \%)$ third dose, $66(18.0 \%)$ and 35 $(9.6 \%)$ of the participants took fourth and first dose, respectively (Table-2).

Table 2: Name of institutions Vs doses of TT vaccine taken by participants ( $\mathrm{n}=366)$, Jan-Mar 2014.

\begin{tabular}{|l|l|l|l|l|l|l|}
\hline \multirow{2}{*}{ Name of Hospitals } & \multicolumn{6}{|c|}{ Vaccine dose } \\
\cline { 2 - 7 } & $1^{\text {st }}$ dose & $2^{\text {nd }}$ dose & $3^{\text {rd }}$ dose & $4^{\text {th }}$ dose & $5^{\text {th }}$ dose & Total \\
\hline Ayder Referral & $5(5.2 \%)$ & $17(17.5 \%)$ & $26(26.8 \%)$ & $19(19.6 \%)$ & $30(30.9 \%)$ & 97 \\
\hline Mekelle & $12(4.1 \%)$ & $25(29.4 \%)$ & $19(22.4 \%)$ & $10(11.8 \%)$ & $19(22.4 \%)$ & 85 \\
\hline Kalkidan & $14(14.9 \%)$ & $26(27.7 \%)$ & $18(19.1 \%)$ & $19(20.2 \%)$ & $17(18.1 \%)$ & 94 \\
\hline Meskerem & $4(4.4 \%)$ & $17(18.9 \%)$ & $18(20 \%)$ & $18(20 \%)$ & $33(36.7 \%)$ & 90 \\
\hline Total & 35 & 85 & 81 & 66 & 99 & 366 \\
\hline
\end{tabular}


The result of this study showed also the extent of self medication among the participants. Thirty eight $(9.5 \%)$ of the participants have utilized modern drugs and 8 $(2.0 \%)$ utilized herbs/traditional medicines to alleviate/treat their symptoms/diseases. From the self medicated participants, majority $26(59.1 \%)$ of them used analgesics. From the modern drugs self medicated, according to United States Food and Drug Administration (US FDA) fetal risk classification, majority $32(84.2 \%)$ were in category $\mathrm{C}$, followed by category B 3 (7.9\%), category B/C 2 (5.3\%), and category C/D $1(2.7 \%)$. The main reason behind taking drugs without prescription was minority of the disease 23 $(5.8 \%)$.

Bivariate Logistic regression analysis was conducted to explore women who were more likely to have used medications of any type without prescription during their pregnancy. Demographic factors (age, marital status, education and occupation of participants) were each tested against the outcome variable (self medications) use during the current pregnancy. No significant association was found with the participant's age but the other socio-demographic factors (Marital status, education level and occupation) have shown significant association with the dependent variable (self medication) (Table-3).

Multivariate logistic regression was performed for variables that showed significant association during bivariate analysis with medications use without prescription. The variables that were included in the final analysis were marital status, educational level and occupation of the participants. It was found that marital status of participants did not have significant association with the dependent variable; but educational level had showed significant association in which the illiterate participants were 3.7 times more to practice self medication (AOR $3.65(1.31,10.20), \mathrm{p}=0.014)$ and participants who completed secondary school were four times more to practice self medication (AOR 4.03 (1.09, 14.96), $\mathrm{p}=0.038$ ) compared with the tertiary complete pregnant women. The occupation of the participants had also significant association with practicing self medication; where the participants employed in nongovernmental organization were 3.7 times more able to practice self medication (AOR 3.68 (1.11, 12.17), $\mathrm{p}=0.033)$ compared with the participants employed in governmental organizations (Table-3).

Table 3: Binary and multivariate logistic regression analysis of Self medication Vs socio-demographic factors of the participants, Jan-Mar 2014.

\begin{tabular}{|c|c|c|c|c|c|c|}
\hline \multirow{2}{*}{$\begin{array}{l}\text { Characteristics of } \\
\text { participants }\end{array}$} & \multicolumn{2}{|c|}{ Self-medication, $\mathrm{n}(\%)$} & \multirow[b]{2}{*}{$\operatorname{COR}(95 \% \mathrm{CI})$} & \multirow{2}{*}{$\begin{array}{l}\text { p- } \\
\text { value }\end{array}$} & \multirow[b]{2}{*}{$\operatorname{AOR}(95 \% \mathrm{CI})$} & \multirow{2}{*}{$\begin{array}{l}\text { p- } \\
\text { value }\end{array}$} \\
\hline & Yes & No & & & & \\
\hline \multicolumn{7}{|l|}{ Age } \\
\hline $15-25$ & $17(10.0)$ & $153(90)$ & 1 & & - & - \\
\hline $26-36$ & $21(10.6)$ & $178(89.4)$ & $1.06(0.54,2.09)$ & 0.862 & - & - \\
\hline$\geq 37$ & $5(16.1)$ & $26(83.9)$ & $1.73(0.59,5.10)$ & 0.320 & - & - \\
\hline \multicolumn{7}{|l|}{ Marital status } \\
\hline Married & $37(9.7)$ & $345(90.3)$ & 1 & & 1 & \\
\hline Single & $4(30.8)$ & $9(69.2)$ & $4.2(1.2,14.1)$ & 0.23 & $3.78(0.96,14.85)$ & 0.057 \\
\hline Divorced/widowed & $2(40.0)$ & $3(60.0)$ & $6.2(1.0,38.4)$ & 0.049 & $5.09(0.69,37.39)$ & 0.109 \\
\hline \multicolumn{7}{|l|}{ Educational level } \\
\hline Illiterate & $8(16.7)$ & $40(83.3)$ & $3.22(1.26,8.20)$ & 0.015 & $3.65(1.31,10.20)$ & 0.014 \\
\hline Read \& write & $2(7.1)$ & $26(92.9)$ & $2.92(1.09,7.87)$ & 0.034 & $2.77(0.92,8.35)$ & 0.070 \\
\hline Primary complete & $11(13.4)$ & $71(86.6)$ & $1.45(0.29,7.38)$ & 0.654 & $1.38(0.23,8.32)$ & 0.727 \\
\hline Secondary complete & 15 (14.6) & $88(85.4)$ & $3.77(1.28,11.04)$ & 0.015 & $4.03(1.09,14.96)$ & 0.038 \\
\hline Tertiary complete & $7(5.0)$ & $132(95.0)$ & 1 & & 1 & \\
\hline \multicolumn{7}{|l|}{ Occupation of participants } \\
\hline Government employee & $5(5.3)$ & 89 (94.7) & 1 & & 1 & \\
\hline Non government employee & $11(22.4)$ & $38(77.6)$ & $5.16(1.68,15.85)$ & 0.004 & $3.68(1.11,12.17)$ & 0.033 \\
\hline Merchant & $5(8.8)$ & $52(91.2)$ & $1.71(0.48,6.19)$ & 0.413 & $0.99(0.99,0.25)$ & 0.992 \\
\hline Student & $2(8.7)$ & $21(91.3)$ & $1.70(0.31,9.35)$ & 0.545 & $0.82(0.14,4.94)$ & 0.825 \\
\hline Housewife & $17(11.6)$ & $130(88.4)$ & $2.33(0.83,6.54)$ & 0.109 & $1.32(0.41,4.28)$ & 0.646 \\
\hline Unemployed & $3(10.0)$ & $27(90.0)$ & $1.98(0.45,8.82)$ & 0.371 & $0.80(0.14,4.59)$ & 0.803 \\
\hline
\end{tabular}

Among all the participants, $41(10.2 \%)$ of them had chronic diseases. Most $21(50.0 \%)$ of the participants with chronic diseases were patients living with HIV/AIDS who took antiretroviral therapy; from these $20(48.8 \%)$ were those who visited Mekelle hospital for antenatal care, 18 (43.9\%) Ayder referral hospital and 3 $(7.3 \%)$ kalkidan hospital. Ten $(23.8 \%)$ were hypertensive patients taking antihypertensive drugs; 7 (70\%) and 3 (30\%) of them were from Ayder referral hospital and
Mekelle hospital, respectively. From all the drugs taken by the patients with chronic diseases, according to US FDA fetal risk classification, $26(39.4 \%)$ were from category C, 17 (25.8\%) category D, $13(19.7 \%)$ category $\mathrm{B}$, and $10(15.2 \%)$ were from category $\mathrm{B} / \mathrm{C}$.

From all the participants, 249 (62.2\%) have consumed one or more prescription drugs during their present pregnancy. The number of drugs prescribed per pregnant 
women on average was $1.86 \pm 0.94$. Most $103(26 \%)$ of the participants were prescribed with one drug (Table-4).

Table 4: Number of drugs prescribed per pregnant women (n=249), Jan-Mar 2014.

\begin{tabular}{|c|c|c|}
\hline No. of drugs & Frequency & Percent \\
\hline 1 & 103 & 41.4 \\
2 & 96 & 38.6 \\
3 & 36 & 14.5 \\
4 & 10 & 4.0 \\
5 & 3 & 1.2 \\
6 & 1 & .4 \\
Total & 249 & 100.0 \\
\hline
\end{tabular}

When all the prescribed drugs were categorized according to US FDA fetal risk classification; most 190
$(76.3 \%)$ were in category B, followed by category C 94 (37.8\%), category A $53(21.3 \%)$, category C/D 23 (9.2\%), category D $22(8.8 \%)$, category B/C 7 (2.8\%), category A/C $3(1.2 \%)$ and category X $1(0.4 \%)$. From the drugs prescribed, $101(40.6 \%)$ were prescribed in Ayder referral hospital at which majority 80 (32.1\%) were from category B, followed by category C 40 $(16.1 \%)$. Ninety three $(37.3 \%)$ of the drugs were prescribed in Mekelle hospital where majority 71 $(28.5 \%)$ were in category B and $46(18.5 \%)$ were in category $\mathrm{C}$. Thirty one $(12.4 \%)$ of them were prescribed in kalkidan hospital, majority $21(8.4 \%)$ were in category $\mathrm{B}$, and $24(9.6 \%)$ were prescribed in Meskerem hospital where most $18(7.2 \%)$ lied in category B (Table-5). Most $104(26.0 \%)$ of the drugs were prescribed by general practitioners and the only drug from category $\mathrm{X}$ was prescribed by a nurse in Ayder referral hospital.

Table 5: Category of the prescribed drugs in the four study hospitals ( $\mathrm{n}=249)$, Jan-Mar 2014.

\begin{tabular}{|l|l|l|l|l|l|}
\hline $\begin{array}{l}\text { Category } \\
\text { prescribed drugs }\end{array}$ & of & Name of Hospitals & \multicolumn{2}{|l|}{} \\
\cline { 2 - 5 } & $\begin{array}{l}\text { Ayder referral } \\
\text { hospital }\end{array}$ & $\begin{array}{l}\text { Mekelle } \\
\text { hospital }\end{array}$ & $\begin{array}{l}\text { Kalkidan } \\
\text { hospital }\end{array}$ & $\begin{array}{l}\text { Meskerem } \\
\text { hospital }\end{array}$ & Total \\
\hline Category A & $12(4.8 \%)$ & $18(7.2 \%)$ & $14(5.6 \%)$ & $9(3.6 \%)$ & $53(21.3 \%)$ \\
Category A/C & $3(1.2 \%)$ & $0(0.0 \%)$ & $0(0.0 \%)$ & $0(0.0 \%)$ & $3(1.2 \%)$ \\
Category B & $80(32.1 \%)$ & $71(28.5 \%)$ & $21(8.4 \%)$ & $18(7.2 \%)$ & $190(76.3 \%)$ \\
Category B/C & $4(1.6 \%)$ & $3(1.2 \%)$ & $0(0.0 \%)$ & $0(0.0 \%)$ & $7(2.8 \%)$ \\
Category C & $40(16.1 \%)$ & $46(18.5 \%)$ & $4(1.6 \%)$ & $4(1.6 \%)$ & $94(37.8 \%)$ \\
Category C/D & $8(3.2 \%)$ & $9(3.6 \%)$ & $5(2.0 \%)$ & $1(0.4 \%)$ & $23(9.2 \%)$ \\
Category D & $2(0.8 \%)$ & $9(3.6 \%)$ & $7(2.8 \%)$ & $4(1.6 \%)$ & $22(8.8 \%)$ \\
Category X & $1(0.4 \%)$ & $0(0.0 \%)$ & $0(0.0 \%)$ & $0(0.0 \%)$ & $1(0.4 \%)$ \\
Total & $101(40.6 \%)$ & $93(37.3 \%)$ & $31(12.4 \%)$ & $24(9.6 \%)$ & 249 \\
$(100.0 \%)$ \\
\hline
\end{tabular}

The most commonly used prescription drugs were antibacterial drugs 146 (38.7\%), followed by vitamins and minerals $65(17.2 \%)$ and analgesics 55 (14.6\%) (Table-6).

Table 6: Class and Percentage of the prescribed drugs (n=377), Jan-Mar 2014.

\begin{tabular}{|l|l|l|}
\hline \multirow{2}{*}{ Class of the prescribed drugs } & Response \\
\cline { 2 - 3 } & $\mathrm{N}$ & Percent \\
\hline antibacterial drugs & 146 & $38.7 \%$ \\
vitamin \& minerals & 65 & $17.2 \%$ \\
analgsic drugs & 55 & $14.6 \%$ \\
antiemetic drugs & 23 & $6.1 \%$ \\
drugs acting in git (antacids, ppi, H-2 & 22 & $5.8 \%$ \\
blockers) & & \\
anti retroviral drugs & 13 & $3.4 \%$ \\
antihypertensive drugs & 12 & $3.2 \%$ \\
antidiabetic drugs & 3 & $0.8 \%$ \\
antifungal drugs & 3 & $0.8 \%$ \\
sedative drugs & 11 & $2.9 \%$ \\
Glucocorticoids & 14 & $3.7 \%$ \\
other class drugs & 10 & $2.7 \%$ \\
Total & 377 & $100.0 \%$ \\
\hline
\end{tabular}

\section{DISCUSSION}

Medications are used therapeutically for the purpose of diagnosis, prophylaxis and treatment of diseases. But if they are used inappropriately and untimely they have unwanted effects to the consumers. Especially when drugs are prescribed or self utilized during pregnancy high care should be given because the drugs (C) 2011-14, JDDT. All Rights Reserved administered to the pregnant women can have adverse effect to the unborn fetus. They can cause teratogenic, embryotoxic, and carcinogenic effects and also can cause dependency to the drugs after delivery ${ }^{7}$.

According to the result of this study from the total 400 pregnant women participated, 366 (91.5\%) were vaccinated. Vaccination during pregnancy is useful as ISSN: 2250-1177 
prophylaxis from infection of the life threatening bacteria called clostridium tetani to the mother and to the fetus. Two hundred thirty two (58\%) of the participants took supplementation during their current pregnancy. Taking vitamin and mineral supplementation is beneficial to prevent the mother and the fetus from deficiencies of the vital vitamins and minerals that can cause diseases like anemia to the mother and birth defects to the fetus e.g. deficiency of folic acid causes spina bifida (defect in structure of spinal cord). During pregnancy the need for the minerals and vitamins increases due to the fact that it should satisfy the need of both the mother and the fetus ${ }^{7}$.

Result of this study was very difficult to compare with other study results because of the following reasons: variation on classification of medication categories \& variation in medication use between countries, inconsistency of methodology used (prescription paper collection, reviewing charts, reviewing medical card records, etc),variation in health care setting where the studies conducted, variation in prescribing practices between developing and developed countries and variation of prescribers qualification.

This study showed that $9.5 \%$ of the participants have self medicated with modern drugs and $2.0 \%$ took traditional medicines/herbs to treat their symptoms. This result was similar to the studies done in Peru $(10.5 \%)^{11}$, Addis Ababa $(12.4 \%)^{12}$ and to the study done in Ethiopia $(15.0 \%)^{13}$. But the finding of this study was lower than the study done in Jimma University specialized hospital $(20.1 \%){ }^{14}$.The result of this study was very low when compared with the study done in Nigeria's three general hospitals $(72.4 \%)^{15}$. The possible reasons could be sample size difference and there could be more lack of awareness in Jimma and Nigerian pregnant women on the risks of drug use during pregnancy than this study participant. In this study there was significant association between self medication and educational level; where the illiterate and secondary school complete participants practiced self medication 3.7 times (AOR 3.65 (1.31, 10.20) with $\mathrm{p}=0.014$ and 4.0 times (AOR 4.03 (1.09, 14.96 ) with $\mathrm{p}=0.038$, more than the tertiary complete participants, respectively. This might be due to lack of knowledge about the risk of using drugs without consulting health professional during pregnancy and may be more prone to listen advice of other lay man people around them than consulting health professionals. Occupation of participants, non government employed were 3.7 times (AOR $3.68(1.11,12.17)$ with $p=0.033$ more to practice self medication compared with the government employed ones. This might be due to lack of right information on the harm of the drugs and may be economically in better status than the governmental employed once that can enable them to easily buy drugs.

This study have shown that out of the total 400 participants, $249(62.2 \%)$ have used prescription drugs. With average number of drugs prescribed per pregnant women of $1.86 \pm 0.94$. This finding was comparable with a study done in Ethiopia (55.2\%) ${ }^{13}$ and Sweden (57.6\%) 16

According to the US FDA fetal risk classification of drugs, majority of the prescribed drugs, 190 (76.3\%) were from category B followed by category C 94
(37.8\%), category A $53(21.3 \%)$, category C/D 23 $(9.2 \%)$, category D $22(8.8 \%)$ and category X $1(0.4 \%)$. Some drugs are classified in category $\mathrm{C} / \mathrm{D}, \mathrm{B} / \mathrm{C}$, and $\mathrm{A} / \mathrm{C}$; depending on the time of administration (e.g. ibuprofen and diclofenac are classified in category $\mathrm{C}$ when administered before 30 weeks of gestation but they are category D drugs if administered after 30 weeks of pregnancy), variation on route of administration (e.g. methyldopa is category B drug but when administered in injection form it is in category C) and/or variation of manufacturer (e.g. magnesium sulphate is classified in category A or $\mathrm{C}$ depending on the manufacturer). According to one study when non steroidal antiinflammatory drugs are administered in the second and third trimester of pregnancy they are significantly associated with low birth weight, asthma of 18 month old children and maternal vaginal bleeding (17). This finding have shown lower prescription of harmful drugs from category D $(8.8 \%)$ and category X $(0.4 \%)$ than the study done in Ethiopia where $16.8 \%$ were Category $\mathrm{D}$ and $7.1 \%$ Category $\mathrm{X}^{13}$, but higher than the study done in United States (4.8\%) ${ }^{18}$ and Canada $(5.5 \%){ }^{19}$ of prescribing harmful drugs from category $\mathrm{D}$, but a bit lower pattern of prescription from category $X(0.4 \%)$ than in United states $(4.6 \%)^{18}$ and Canada $(2.5 \%){ }^{19}$. These variations might be due to lack of knowledge, training and experience of prescribers or variation in sample size of this study than the studies in United States and Canada for prescribing category D drugs and viceversa for category $\mathrm{X}$ prescription.

Majority of the prescribed drugs in this study were antibacterial medications $146(38.7 \%)$, followed by vitamins and minerals $65(17.2 \%)$, and analgesics 55 (14.6\%) (Table-6). Majority of prescribed drugs in the current study being antibacterial makes it comparable with a study done in Ethiopia $(42.5 \%)^{13}$. The possible reasons of higher rate of antibacterial drug prescription might suggest that the pregnant women's common indications were microbial infections which are actually common in our setup.

The current study included four hospitals with equal number of participants in the study (100 pregnant women from each). Two of the hospitals were governmental (Ayder referral hospital and Mekelle hospital) and the other two nongovernmental (Kalkidan and Meskerem hospital). From all the drugs prescribed majority 101 $(40.6 \%)$ of them were prescribed in Ayder referral hospital followed by Mekelle hospital 93 (37.3\%), Kalkidan hospital 31 (12.4\%) and Meskerem hospital 24 $(9.6 \%)$. The reason behind could be lack of updated knowledge of prescribers working in governmental hospitals than private hospitals. Moreover in private hospitals treatments are mostly given by senior professionals. In governmental hospitals commonly general practitioners, where majority $104(26.0 \%)$ of the drugs were prescribed, and nurses are involved in prescription. In addition to the reasons mentioned above, higher number of drug prescription in Ayder referral hospital could be possibly it accepts referred patients from other governmental and nongovernmental health institutions that are mostly critically ill. Majority of the drugs prescribed in each hospital were from category B; $32.1 \%, 28.5 \%, 8.4 \%$ and $7.2 \%$ in Ayder referral hospital, 
Mekelle hospital, Kalkidan and meskerem hospitals, respectively. From the total prescribed category D drugs (8.8\%), Majority (3.6\%) were prescribed in Mekelle hospital followed by Kalkidan hospital $(2.8 \%)$ (Table5). This could be due to lack of knowledge and training of the prescribers on the risk of prescribing drugs to pregnant women. Safety of majority of the prescribed drugs was fine to be taken during pregnancy depending on the risk benefit ratio. The only drug from category $\mathrm{X}$ (ergometrin) was prescribed by a nurse in Ayder referral hospital.

There is no safe drug to be prescribed during pregnancy due to the fact that none of the drugs in the market are tested in pregnant women before marketing. So prescribing of drugs during pregnancy should be based on the risk benefit ratio (drugs should be prescribed to pregnant women if and only if the benefit outweighs the risk from the drug to the mother/fetus). This pattern of prescription by level of qualification might show that to prescribe relatively safe drugs during pregnancy needs deep knowledge and experience on pharmacological property of the drugs.

\section{CONCLUSION and RECOMMENDATIONS}

From this study it can be concluded that majority of the prescribed drugs were from category $\mathrm{B}$ followed by

\section{REFERENCES}

1. FMOH, Planning and Programming Department (2006/2007).Health and health related indicators. Addis Ababa, Ethiopia.

2. WHO, UNFPA, UNICEF, World Bank (1999).Reduction of maternal mortality: a joint WHO/UNFPA/UNICEF/World Bank statement. Geneva.

3. FMOH, Family health department (2006).Report on safe mother hood community- based survey. Federal Ministry of Health, Ethiopia.

4. Eze UI, Eferakeya AE, Oparah AC, Enato EF (2007).Pharmacy practice. Assessment of prescription profile of pregnant women visiting antenatal clinics.

5. Das B, Sarkar C, Datta A, Bohra S (2003).Pharmacoepidemiol drug staf. A study of drug use during pregnancy in a teaching hospital in western Nepal.

6. Benjamin DM (2003). Reducing medication errors and increasing patient safety: case studies in clinical pharmacology. J ClinPharmacol, 43:768-783.

7. Kacew S (1994). Fetal consequences and risks attributed to the use of prescribed and over-the-counter (OTC) preparations during pregnancy. Int $\mathrm{J}$ ClinPharmacolTher, 32:335-243.

8. Koren G, Pastuszak A, Ito S (1998): Drugs in pregnancy. N Eng J Med, 338:1135-1137.

9. WHO, University of Amsterdam, Royal tropical institute (2004).How to investigate the use of medicines by consumers.

10. Beyens MN, Guy C, Ratrema M, Ollagnier M (2003). Prescription of drugs to pregnant women in France: the HIMAGE study. Therapie, 58:505-511.

11. Mini, Elsy et al. Self-medication behavior among pregnant women user of the Instituto Nacional Materno Perinatal, Peru 2011. Rev Peru Med Exp Salud Publica [online]. 2012, vol.29, n.2, pp. 212-217. category C. But higher percentage was also from category D and one drug from category X. Extent of self medication was also high.

At any time of prescribing or dispensing drugs during pregnancy cautions should be given. Due to the fact that the prescribed or self utilized drugs can harm the fetus. Continuous updated education should be given to the health professionals so that they can comply with the safe prescription of drugs during pregnancy based on the risk benefit ratio like referring to US FDA fetal risk classification of drugs before prescribing. Public education through different ways should also be achieved to increase awareness on safe use of drugs especially during pregnancy. Further studies should be done in health centers and health posts to see the extent of prescription during pregnancy.

CONFLICT OF INTEREST: No conflict of interest was obtained.

\section{ACKNOWLEDGMENT}

I am much honored to thank my institution, Mekelle University, for granting this work. I want to thank also the participants for their willingness to participate in the study by understanding the benefit from it.

12. Kebede B, Gedif T and Getachew A. Assessment of drug use among pregnant women in Addis Ababa, Ethiopia. Pharmacoepidemiol Drug Saf.2009 Jun; 18(6):462-8. doi: $10.1002 /$ pds. 1732

13. Mohammed Adem Mohammed, Jemal Hussein Ahmed, Abdulhalik Workicho Bushra, Hisham S. Aljadhey. Medications use among pregnant women in Ethiopia: A cross sectional study. Journal of Applied Pharmaceutical Science Vol. 3 (04), pp. 116-123, April, 2013. DOI: 10.7324/JAPS.2013.3421.

14. Abdi Befekadu, Nezif Hussein Dhekama, Mohammed Adem Mohammed. Self-medication and Contributing Factors among Pregnant Women Attending Antenatal Care in Ethiopia: The Case of Jimma University Specialized Hospital. Med-science. 2014; 3(1): 969-81. doi: 10.5455/medscience.2013.02.8098.

15. Festus Abasiubong, Emem Abasi Bassey,and Alphonsus Udo Idung. Self-Medication: potential risks and hazards among pregnant women in Uyo, Nigeria.Pan Afr Med J.2012; 13-15.

16. Stephansson O, Granath F, Svensson T, Haglund B, Ekbom A, Kieler H. Drug use during pregnancy in Sweden - assessed by the Prescribed Drug Register and the Medical Birth Register. Clinical Epidemiology 2011; 3: 43-50.

17. Nezvalová - Henriksen K, Spigset O, Nordeng H. Effects of ibuprofen, diclofenac, naproxen, and piroxicam on the course of pregnancy and pregnancy outcome: a prospective cohort study. BJOG. 2013 Jul; 120 (8):948-59.

18. Susan E, Andrade ScD, jerry H, Robert L et al. Prescription drug use in pregnancy. American Journal of Obstetrics \& Gynecology 2004; 191 (2): 398-407.

19. Daw JR, Mintzes B, Law MR, Hanley GE, Morgan SG. Prescription drug use in pregnancy: a retrospective, population-based study in British Columbia, Canada (20012006). Clin Ther. 2012 Jan; 34(1):239-249.e2. doi: 10.1016. 